\title{
As ações de extensão e suas contribuições para o discente de Pedagogia da Universidade Federal do Ceará
}

\author{
Marcos Antonio Martins Lima \\ marcos.a.lima@terra.com.br \\ Ana Paula Vasconcelos de Oliveira Tahim \\ anapaula_tahim@yahoo.com.br \\ Denize de Melo Silva \\ denisemellopedagoga@gmail.com \\ Universidade Federal do Ceará | Brasil
}

\section{Resumo}

Este trabalho debruça-se sobre as ações de extensão desenvolvidas pela Universidade Federal do Ceará para a formação de seus discentes. A abordagem metodológica embasa-se na proposta de Bruyne et al. (1977). Esta pesquisa enquadra-se como exploratória e descritiva, de cunho quantitativo e qualitativo, tendo como lócus o Campus do Benfica e amostra populacional os discentes do terceiro ao sétimo semestre do curso de Pedagogia. Quanto ao aspecto quantitativo, a análise dos dados foi realizada utilizando o Statistical Package for the Social Sciences. Mediante essa construção, observase a importância da participação em ações extensionistas no processo de construção da formação acadêmico-profissional dos estudantes da referida universidade.

\section{Palavras-chave}

Extensão universitária; Formação acadêmica; Pedagogia. 


\section{Introdução}

O presente estudo preocupa-se com as contribuições advindas das ações de extensão realizadas pela Universidade Federal do Ceará (UFC), bem como sua relação para a formação dos estudantes do curso de licenciatura plena em Pedagogia desta. Nesse contexto, percebe-se a relevância das ações da universidade embasadas no tripé ensino, pesquisa e extensão e sua relação direta na formação dos discentes do referido curso.

Buscam-se mudanças estruturais em macrocontextos como a produção do conhecimento e consolidação de uma prática adequada de promoção do saber científico. Assim, a universidade deve constituir-se como lócus de distribuição do conhecimento, promover compromisso e admitir que a universidade não é uma instituição restrita, mas integrada à comunidade (ANDRIOLA, 2005). Dessa forma, entende-se que determinadas ações devem desencadear um avanço qualitativo para a formação do profissional, atrelando-se ao ensino e à base prática na atuação dos profissionais em formação. Nesse viés, o estudo visa contribuir com as práticas extensionistas desenvolvidas com vistas à formação e aos mecanismos adotados pela universidade a fim de que se fortifiquem saberes coletivos ligados à realidade dos estudantes.

Assim, a pergunta que direciona este estudo é: como as atividades de extensão têm acontecido no curso de Pedagogia da UFC de forma a contribuir com sua formação? Diante disso, pretende-se verificar a compreensão dos alunos provenientes do curso de licenciatura plena em Pedagogia da UFC sobre os conceitos e atividades extensionistas desenvolvidos pela referida instituição.

Para tanto, pretende-se embasar a construção deste trabalho na estratégia metodológica quadripolar proposta por Bruyne et al. (1977), que trata de um desdobramento em quatro polos de investigação: epistemológico, teórico, morfológico e técnico. Dessa forma, o estudo se pauta em categorias como: ação universitária, formação acadêmica e Pedagogia.

\section{Polo epistemológico: discussão filosófica}

Max Weber (1963) insere-se no debate ideológico sobre as reflexões 
metodológicas nas ciências sociais e centra-se no sujeito de ação. Nesse embate, a sociologia interpretativa considera o indivíduo e o seu ato como unidade básica. $\mathrm{Na}$ abordagem, o indivíduo é também o portador de conduta significativa. As ações são exemplificadas por Weber (1963) como categorias a serem constituídas como dados por meio da relação social em que emergem. Nesse limiar, observa-se que os elementos tradicionais dados pelo referido sociólogo são concebidos como uma ação racional aos meios empregados, mas irracional em relação aos fins almejados.

Os tipos de ações, para Weber (2001), são constituídos operacionalmente nessa escala de racionalidade e irracionalidade. 0 referido autor traça uma linha entre a sociologia interpretativa, sendo as estruturas sociais desenvolvidas pela sociedade, portanto essas estruturas são associadas e interligadas à comunidade. Sendo assim, possuem relação direta aos tipos de ação propostos em suas ações.

Nesse contexto, busca-se compreender as ações de extensão realizadas pela UFC, na perspectiva discente, embasada na sociologia compreensiva epistemológica de Max Weber (2001). Para tanto, pretende-se empreender as categorias de análise teórica a fim de visualizar os impactos gerados por essas ações.

\section{Polo teórico: discussão teórica}

Conforme Lima (2008), a teoria é um corpo de conhecimento que permite organizar, categorizar, descrever, predizer, explicar, isto é, ajudar a compreender e a controlar determinado assunto pautado na orientação teórica que irá assegurar a compreensão e o controle do objeto em aprofundamento e análise.

\subsection{Avaliação do modelo de extensão da UFC}

Dada a complexidade das variáveis a serem observadas, pretende-se, no referido tópico, discorrer sobre o modelo de extensão em que se baseiam as construções das ações de extensão provenientes da referida instituição de sorte a realizar uma avaliação pautada na construção e determinação dos objetivos a serem alcançados.

Diante disso, verifica-se, segundo o modelo de avaliação proposto por Stake (1942), que a avaliação tem o papel de discorrer sobre a realidade, verificando a 
extensão e a qualidade dos serviços ofertados. Nesse caminhar, atua para o desenvolvimento de programas ou ações destinados às necessidades das instituições envolvidas nesse processo.

Nessa construção, cabe averiguar, conforme Vianna (2000), que a avaliação formal caracteriza-se pela dependência de observações, objetivos implícitos, normas intuitivas e julgamentos subjetivos, traduzindo elementos, comparações e uso de instrumentos padronizados para a compreensão dos fenômenos observados.

Outro aspecto que embasa a avaliação, segundo as contribuições de Stake (1942), é denominada de lado informal da avaliação. Esse aspecto seria realizado com base nas observações e opiniões sobre determinado assunto para a compreensão do fenômeno em estudo.

Avaliação informal, com base na opinião de professores sobre o programa, a lógica e/ou a reputação profissional responsável pela elaboração provoca, naturalmente, uma insatisfação em relação à avaliação formal, existindo poucos estudos desse tipo de avaliação que sejam realmente significativos na percepção de Robert E. Stake, que também põe em dúvida a contribuição dessa avaliação para a educação. (VIANNA, 2000, p. 127).

Nesse contexto, consideram-se importantes para a prática avaliativa o julgamento e a descrição das ações desenvolvidas pelo programa para o norteamento dos trabalhos realizados para a validação das ações que já são elaboradas pela instituição e para o melhoramento dos aspectos avaliativos adjacentes a essa prática. Esse conjunto de ações será realizado com base nos dados relacionados à coleta de dados, devendo, consoante Stake (1967), obedecer aos três conjuntos de informações para uma análise eficiente.

O primeiro conjunto visa discutir sobre as condições para que essas ações sejam colocadas em prática, denominado comportamento de entrada. 0 segundo conjunto de informações atrela-se às interações entre os componentes ou comunidade que integram esse processo interativo. 0 terceiro conjunto compreende os conhecimentos, as habilidades e as atitudes inerentes às experiências educativas. Para Vianna (2000, p. 41), esse modelo sugere o aprofundamento e identificações de variáveis favoráveis à compreensão das ações desenvolvidas nesse contexto:

Identificar o que é comum e o que é singular em um caso, ainda que muitos estudos de caso acabem apresentando dados sobre a natureza do mesmo, suas origens históricas, seu contexto físico e outros contextos (econômico, político, 
legal e até mesmo estético), tendo em vista que o caso é uma entidade de natureza complexa, apesar de sua singularidade, e justamente tendo em vista essa complexidade o estudo de caso deve ser de natureza holística.

A fim de contextualizar as práticas adjacentes à universidade como lócus de produção de saberes, cabe, pois, a investigação acerca dos modelos institucionais para a compreensão das ligações geradas a partir das intervenções realizadas e seus impactos para a dissipação desses saberes e para a ampliação das oportunidades oferecidas aos discentes que integram esses espaços. Corroborando o processo, verifica-se que essa construção possibilitará a sedimentação da avaliação, conforme Demo (2010), como processo contínuo que não deve ser fragmentado em etapas relacionadas somente ao ensino.

A avaliação dos modelos de ações da Pró-Reitoria de Extensão da UFC constitui-se como processo intencional embasado em diversos mecanismos de aplicabilidade da mesma, não restringindo esse processo como inerente somente à escola na qualidade de instituição em que se processa o saber. Nesse contexto, constitui-se como base para a análise das ações de extensão desenvolvidas pela UFC, sendo importante considerar as resoluções de norteamento direcionadas pela Pró-Reitoria de Extensão da referida instituição. Esse processo consolidará a compreensão das atividades desenvolvidas e se essas ações são coerentes e condizentes com as terminologias e os conceitos empregados na discussão empreendida.

Diante disso, segundo Tyler (1942), a educação compreende um processo integrador que articula a criação de padrões de conduta, possibilitando modificações dos padrões adotados anteriormente. Esses padrões adotados nas instituições de ensino estão ligados aos objetivos educacionais propostos a partir das experiências significativas de aprendizagem. De acordo com as diretrizes dos princípios e objetivos traçados para as ações da Pró-Reitoria de Extensão da UFC, este é o objetivo central das ações de extensão:

Art. 1o As atividades de extensão na Universidade Federal do Ceará - UFC têm como objetivo primordial promover uma relação mutuamente transformadora entre a universidade e a sociedade, articulando ensino e pesquisa por meio da cultura, arte, ciência, tecnologia e inovação, tendo em vista o desenvolvimento social. (UFC, 1996, p. 1).

As diretrizes atuam como direcionamentos das ações desenvolvidas por 
intermédio da orientação quanto à categoria processual a ser desenvolvida nas relações entre a própria universidade nos setores sociais. Nesse contexto, a transdisciplinaridade envolve a contribuição para as atividades de extensão, sendo especialmente feitas para as devolutivas aos setores da sociedade, ou seja, os grupos sociais que integram a rede de participação dessas atividades que são promovidas pelo acesso quantitativo e qualitativo das ações extensionistas.

Outro aspecto relacionado ao modelo de extensão adotado para a reflexão decorrente do modelo adotado na referida instituição é o contexto de interlocução entre ensino, pesquisa e extensão. Nesse sentido, constituem-se como processo formativo e geração de saberes como diálogo permanente das ações e áreas de conhecimento.

\subsection{Contribuições do curso de Pedagogia da UFC para o discente}

Sobre as diretrizes do curso de licenciatura plena em Pedagogia da UFC, observase que as mesmas desempenham funções essenciais que visam à promoção e acesso dos estudantes ao saber científico estruturado e sistematizado que devem ser proporcionados pela referida instituição. Nessa construção, cabe analisar as contribuições de tais diretrizes para a ampliação da atuação desse profissional para além do contexto escolar, interligando suas ações em outras modalidades de ensino. Esse contexto sugere a abrangência de conceitos.

Diante disso, cabe refletir sobre o impacto dessas diretrizes para o próprio curso e sua organização devidamente pautada nas entrelinhas dos objetivos planejados e pensados para o curso de pedagogia da UFC e suas influências na formação dos discentes imersos nessa construção. Para isso, pretende-se "Formar para o exercício das funções de magistério na Educação Infantil e nos anos iniciais do Ensino Fundamental e para a gestão de processos escolares e não escolares, tendo como eixos centrais a docência, pesquisa e extensão" (UFC, 2013, p. 18).

\section{Polo morfológico: apresentando o modelo}

Neste momento, faz-se necessária a apresentação do modelo que simule os problemas reais que trazem regras de estruturação e de formulação do objeto científico, 
para, assim, perceberem-se estruturas existentes para o estudo. Para tanto, nesse contexto será analisado o modelo de extensão da Universidade Federal do Ceará (UFC) com base nas diretrizes regulamentadoras expressas pela instituição que regulamentam as ações de extensão e sua importância para a formação discente.

\subsection{Ações de extensão}

A Resolução no 4, do Conselho de Ensino, Pesquisa e Extensão (CEPE), estabelece as normas e diretrizes essenciais que orientam as atividades extensionistas da UFC. Assim, denomina-se extensão o conjunto de ações de caráter orgânico-institucional, de médio a longo prazo, com clareza de diretrizes e orientadas a um objetivo comum, articulando projetos e outras ações existentes, inclusive de ensino e pesquisa.

A extensão observada, como princípio constitucional inerente ao ensino e pesquisa, constitui-se como processo interdisciplinar, educativo, cultural, científico e político que promove a interação transformadora entre a universidade e outros setores. Nessa construção, cabe elencar as ações desenvolvidas e sua colaboração para a formação dos discentes no que tange às articulações definidas no conceito e nas atividades realizadas. A Pró-Reitoria de Extensão apresenta as seguintes ações que podem ser desenvolvidas no âmbito acadêmico: a) programa; b) projeto; c) cursos; d) prestação de serviços; e e) eventos.

A ação extensionista denominada "programa" corresponde às ações de caráter orgânico-institucional, de médio a longo prazo, com clareza de diretrizes e orientadas a um objetivo comum. A ação de extensão denominada "projeto" constitui-se como contínua e pautada na ação educacional, científica, cultural e tecnológica, com objetivos definidos e prazos determinados. A ação denominada "curso" corresponde a ações pedagógicas, de caráter teórico e/ou prático, presenciais ou a distância, planejadas e organizadas de maneira sistemática, com carga horária definida e processo de avaliação formal. As prestações de serviços oferecidas como "cursos" devem ser registradas como tais. Os registros de cursos poderão ser classificados como iniciação, atualização, qualificação profissional e aperfeiçoamento, a depender do critério estabelecido por cada universidade. Em relação aos "eventos", podem ser considerados como ação de interesse técnico, social, científico, esportivo e artístico. Enquadram-se as assembleias, 
campanhas de difusão cultural, campeonatos, ciclos de estudos, circuitos e colóquios. Os registros de eventos poderão ter a classificação detalhada a critério de cada universidade.

Diante do exposto, para mensurar o impacto das ações extensionistas na formação dos discentes do curso de Pedagogia, faz-se necessário perceber a prática avaliativa nessas ações, necessitando, pois, de informações sobre a eficiência e eficácia dos sistemas vinculados ao processo de ensino-aprendizagem.

Dessa forma, Vianna (2000) apresenta a avaliação que, na concepção de Tyler, verificaria a concretização desses objetivos propostos apontando a congruência entre resultados e objetivos das ações extensionistas desenvolvidas. Seria, pois, uma forma de validar os pressupostos teóricos em que se baseia a avaliação dessas ações promovidas pela universidade.

Todas as atividades de extensão deverão ser classificadas conforme a área temática principal e, opcionalmente, conforme a área temática secundária, quando estiverem relacionadas a mais de uma área. A finalidade dessa classificação consiste na sistematização, de maneira a favorecer os estudos e relatórios sobre a produção da extensão universitária brasileira, segundo agrupamentos temáticos, bem como a articulação de indivíduos ou de grupos que atuam na mesma área temática.

As denominadas áreas temáticas sãs divididas de forma uniforme para a utilização em caráter nacional. As áreas temáticas são agrupadas em: comunicação, cultura, direitos humanos e justiça, educação, meio ambiente, saúde, tecnologia e informação e trabalho, totalizando oito áreas temáticas.

A comunicação, primeira área temática, está relacionada com a mídia comunitária, escrita e eletrônica. Dispõe de capacitação e qualificação de recursos humanos e de gestores de políticas públicas de comunicação social para a cooperação interinstitucional e cooperação internacional nas áreas de interesse. A segunda área corresponde à cultura e ao desenvolvimento da memória e do patrimônio, buscando a cooperação internacional na área e acessibilidade das ações extensionistas desenvolvidas.

Os direitos humanos e a justiça, terceira área temática, buscam assegurar a assistência jurídica, ou seja, a capacitação qualificada em recursos humanos e de 
gestores de políticas públicas de direitos humanos, os direitos de grupos sociais, organizações populares e a cidadania, buscando a cooperação interinstitucional e internacional na área.

A quarta área temática atrela-se à educação e visa agregar os conceitos ligados à cidadania, à educação a distância, à educação de jovens e adultos (EJA) e ao incentivo à leitura, capacitação e qualificação dos recursos humanos e de gestores em políticas públicas de educação e cooperação. A quinta área temática vincula-se ao meio ambiente, buscando assegurar a sustentabilidade do meio ambiente e o seu desenvolvimento sustentável. Nesse limiar, agrega aspectos relacionados ao desenvolvimento regional e urbano e à gestão dos recursos naturais.

A saúde configura-se como a sexta área temática, visando à promoção à saúde e à qualidade de vida, bem como à atenção a grupos de pessoas com necessidades especiais e à atenção integral à mulher, à criança, à saúde de adultos, ao idoso, ao adolescente e ao jovem. A tecnologia e a informação, sétima área temática, são responsáveis pela transferência de tecnologias apropriadas para o desenvolvimento do empreendedorismo e inovação tecnológica, buscando a construção de políticas públicas em ciência e tecnologia. A oitava área temática denomina-se trabalho, pois envolve as relações de trabalho como política de inclusão social, além da capacitação e qualificação dos recursos para as organizações populares dos estudantes participantes.

\subsection{Diretrizes do curso de Pedagogia da UFC}

No tocante à interação e à integração dos saberes, as diretrizes contribuem para que:

[...] a participação do estudante em atividades de extensão traga qualidade à sua formação, deve[ndo] estar fundamentada em iniciativas que viabilizem a flexibilização curricular, a integralização dos créditos e a clareza de suas atribuições, bem como deve ser supervisionada pelo coordenador da ação e dispor de uma metodologia de avaliação. (UFC, 1996, p. 2).

Segundo as diretrizes do curso de Pedagogia da UFC, observa-se que a junção entre ensino, pesquisa e extensão constitui-se como elo para a integração e o aperfeiçoamento profissional dos graduandos envolvidos nesse processo. Não restringindo esse saber apenas aos muros da escola, mas abrangendo a significância de 
outros espaços de formação.

Diante desse contexto, cabem as ações extensionistas e o desenvolvimento conjunto da realidade como esfera global de conhecimento na estruturação das competências desejáveis ao estudante do curso de pedagogia da UFC.

As ações que permitem a integração entre ensino, pesquisa e extensão são os estágios e seus respectivos relatórios, os TCC [Trabalhos de Conclusão de Curso], com suas atividades de campo, as diversas atividades de extensão e pesquisa desenvolvidas por professores e alunos e que trazem para a sala de aula essa integração proposta. As bolsas de PIBIC [Programa Institucional de Bolsas de Iniciação Científica], PIBID [Programa Institucional de Bolsa de Iniciação à Docência], extensão e PID [Programa de Iniciação à Docência] também contribuem para a referida integração. (UFC, 2013, p. 17).

A flexibilização empregada na condução do curso visa promover a participação dos estudantes em diversas esferas, além da sala de aula, a fim de gerar uma formação ampla e processual do estudante: “[...] participação e atuação em eventos científicos e culturais, seminários, monitorias, oficinas pedagógicas, palestras, grupos de estudos, dentre outros" (UFC, 2013, p. 18). Dessa forma, a extensão é elemento essencial para a ampliação de possibilidades de formação para esse discente.

\section{Polo técnico: caminhos e debates da pesquisa}

Este polo trata sobre o detalhamento da pesquisa, bem como da apresentação e análise dos dados, momento em que se confronta a teoria que os suscitou.

\subsection{Caminhos da pesquisa}

Nesse contexto, a proposição de um problema, da formulação das hipóteses e da delimitação da amostragem a ser realizada são aspectos inerentes à construção e rigor da pesquisa científica. Nesse limiar, a pesquisa enquadra-se na abordagem descritiva e exploratória. Quando se executa uma pesquisa, mais de um método ou técnica podem ser empregados, usando-se todos os que forem necessários, havendo, por diversas vezes, combinações concomitantes (LAKATOS, 2003).

Esta pesquisa foi realizada na Faculdade de Educação da UFC (Faced/UFC), tendo como população amostral aleatória estudantes do curso de licenciatura plena em Pedagogia. Considerou-se a população total de $n=125$ estudantes do curso de Pedagogia 
da UFC para o cálculo da amostra, sendo o número de amostra de $n=42$ estudantes, no período de maio de 2015. Foram considerados apenas os graduandos que estavam matriculados entre os períodos do $4^{0}$ a a $7^{\circ}$ o semestres e que concordaram em participar do estudo: 42 universitários.

Essa consideração foi realizada com base na premissa de que a participação e o conhecimento dos educandos acerca das ações desenvolvidas pela UFC constituem-se como elementos significativos nesses períodos destacados anteriormente.

Recorre-se aos discentes nessa etapa de construção anteriormente citada por se caracterizar como uma etapa acadêmica importante a ser vivenciada pelo aluno. Nesse limiar, efetivam-se como oportunidades de vinculação as ações de extensão.

A formação de atitudes parece ser uma preocupação constante de todos os responsáveis por desenvolvimento de currículo, pois a expectativa é a de que cada atividade relacionada à aprendizagem contribua para o desenvolvimento de atitudes, além da área curricular específica. (VIANNA, 2000, p. 74).

Outra justificativa atrela-se à orientação concernente à vivência de conceitos indispensáveis para que o aluno possa conhecer o ambiente acadêmico e apropriar-se de experiências que favorecerão a construção de uma base para a sua atuação nas diversas ações extensionistas ofertadas pela referida instituição. Para tanto, pretendeu-se realizar uma construção pautada em um estudo nas abordagens qualitativa e quantitativa com o intuito de mensurar as contribuições advindas das ações de extensão promovidas pela UFC.

Os dados foram coletados através da aplicação de questionário misto com perguntas abertas e fechadas. Na seção A, pretende-se conhecer o perfil do discente do curso de licenciatura plena em Pedagogia da UFC a fim de dimensionar especificidades relacionadas ao gênero, semestre letivo, renda familiar, estado civil e faixa etária dos graduandos em Pedagogia da referida instituição.

Na seção B do referido instrumental adotado, foram realizadas a construção de 10 afirmativas inerentes às ações extensionistas e sua organização na instituição pesquisada. Nesse contexto, as afirmativas englobam as diretrizes traçadas pela UFC para a normatização das ações extensionistas. Diante disso, cabe reiterar que as afirmações guiaram-se pelas inquietudes geradas sobre o impacto dessas ações para a formação do pedagogo no seu processo de formação. 
A escala de percepção adotada na pesquisa está explicitada no quadro 1, visando estabelecer o nível de compreensão dos discentes a respeito das afirmativas contidas no instrumental.

Quadro 1: Escala de percepção

\begin{tabular}{|c|l|}
\hline Escala & \multicolumn{1}{|c|}{ Afirmativas } \\
\hline 0 & Não sei responder \\
1 & Discordo totalmente \\
2 & Discordo parcialmente \\
3 & Concordo parcialmente \\
4 & Concordo plenamente \\
\hline
\end{tabular}

Fonte: Elaboração própria (2016).

No tocante às contribuições das ações extensionistas presentes na instituição, foram elaborados questionamentos sobre o alcance dessas ações e dos impactos pretendidos com o propósito de investigar a integração do estudante de Pedagogia e sua participação ativa nessa construção. Tais aspectos foram contemplados na seção $C$ do instrumental, adotada para a construção desta pesquisa.

Com vistas a interpretar os achados do presente estudo, utilizou-se, para a análise de dados presentes nos instrumentos aplicados quanto ao seu aspecto quantitativo, o software Statistical Package for the Social Sciences (SPSS) versão 19.0.

\subsection{Apresentação e discussão dos resultados}

O presente tópico trata sobre a discussão dos achados da pesquisa, os quais se relacionam às contribuições acerca das etapas que integram as ações de extensão e o seu impacto no curso de licenciatura plena em Pedagogia. Essa construção objetiva tratar sobre os aspectos das ações de extensão que trazem possibilidades quanto às melhorias nos processos realizados na instituição pesquisada e, por conseguinte, colaboram na formação dos discentes do curso de Pedagogia.

5.2.1 Seção A: Perfil da amostra dos discentes do curso de Pedagogia da UFC

Para que se possa entender melhor o envolvimento do aluno com as ações extensionistas apresentadas como auxílio da aprendizagem ao curso de Pedagogia, 
As ações de extensão e suas contribuições para o discente de Pedagogia da Universidade Federal do Ceará

julgou-se pertinente traçar um perfil-base para que se tivesse, assim, um sujeito da pesquisa descrito em auxílio aos dados apresentados. Dessa forma, o quadro a seguir trata da síntese da seção A do instrumento aplicado aos alunos participantes, elaborado para a percepção do perfil da amostra consultada.

Quadro 2: Perfil discente

\begin{tabular}{|c|c|c|}
\hline Semestre & $\mathrm{n}$ 우 & $\%$ \\
\hline 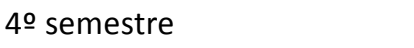 & 2 & $5,0 \%$ \\
\hline 5o semestre & 3 & $7,5 \%$ \\
\hline 60 semestre & 2 & $5,0 \%$ \\
\hline 7ㅇs semestre & 33 & $82,5 \%$ \\
\hline Faixa etária & no & $\%$ \\
\hline 16 a 19 anos de idade & 1 & $2,4 \%$ \\
\hline 20 a 24 anos de idade & 23 & $56,1 \%$ \\
\hline 25 a 29 anos de idade & 7 & $17,1 \%$ \\
\hline 29 anos de idade ou mais & 10 & $24,4 \%$ \\
\hline Gênero & $\mathrm{n}=$ & $\%$ \\
\hline Feminino & 36 & $85,7 \%$ \\
\hline Masculino & 6 & $14,3 \%$ \\
\hline Estado civil & no & $\%$ \\
\hline Solteiro & 25 & $59,5 \%$ \\
\hline Casado & 13 & $31,0 \%$ \\
\hline Outro & 4 & $9,5 \%$ \\
\hline Ano de ingresso & $\mathrm{n}$ 은 & $\%$ \\
\hline 2012 & 37 & $88,1 \%$ \\
\hline 2013 & 4 & $9,5 \%$ \\
\hline 2015 & 1 & $2,4 \%$ \\
\hline Renda familiar & $\mathrm{n}$ 웅 & $\%$ \\
\hline Um salário mínimo & 1 & $2,4 \%$ \\
\hline Dois salários mínimos & 11 & $26,2 \%$ \\
\hline Três salários mínimos ou mais & 30 & $71,4 \%$ \\
\hline
\end{tabular}

\begin{tabular}{|c|c|c|}
\hline Origem escolar & no & $\%$ \\
\hline Escola pública & 17 & $41,5 \%$ \\
\hline Privada & 14 & $34,1 \%$ \\
\hline Ambas & 10 & $24,4 \%$ \\
\hline Cor ou raça & no & $\%$ \\
\hline Branca & 15 & $36,6 \%$ \\
\hline Negra & 4 & $9,8 \%$ \\
\hline Parda & 20 & $48,7 \%$ \\
\hline Outra & 2 & $4,9 \%$ \\
\hline Licenciatura em Pedagogia & no & $\%$ \\
\hline Noturno & 23 & $56,1 \%$ \\
\hline Diurno & 19 & $43,9 \%$ \\
\hline Previsão de conclusão do curso & no & $\%$ \\
\hline 2015 & 10 & $23,8 \%$ \\
\hline 2016 & 23 & $54,8 \%$ \\
\hline 2017 & 8 & $19,0 \%$ \\
\hline 2019 & 1 & $2,4 \%$ \\
\hline $\begin{array}{c}\text { Participação em ação da } \\
\text { extensão UFC }\end{array}$ & no & $\%$ \\
\hline Sim & 13 & $31,0 \%$ \\
\hline Não & 29 & $69,0 \%$ \\
\hline Enquadramento & no & $\%$ \\
\hline Bolsista remunerado & 8 & $19,0 \%$ \\
\hline Voluntário & 3 & $7,1 \%$ \\
\hline Nenhum & 31 & $73,9 \%$ \\
\hline
\end{tabular}

Fonte: Elaboração própria (2016).

Conforme os achados da pesquisa, observou-se, a partir da análise coletada em relação ao semestre letivo do curso de licenciatura plena em Pedagogia, que a maioria dos respondentes pertence ao 7ํㅗ semestre do curso: $82,5 \%(n=33)$, sendo a maioria dos universitários do gênero feminino: $85,7 \%(n=36)$. Sobre o turno em que os estudantes estão matriculados, $56,1 \%(n=23)$ pertencem ao curso noturno, enquanto 43,9\% $(n=19)$ pertencem ao curso diurno. Em relação à faixa etária, verificou-se que a maioria dos discentes está na faixa etária dos 20 aos 24 anos de idade: 56,1\% (n=23). Quanto ao 
estado civil, os estudantes enquadraram-se como solteiros: 59,5\% (n=25). Constatou-se que a maioria dos educandos é oriunda da rede pública de ensino: 41,5\% (n=17). Verificou-se também que 88,1\% ( $\mathrm{n}=37)$ ingressaram em 2012, com a maioria na expectativa de concluir o curso de licenciatura plena em Pedagogia em 2016: 54,8\% $(\mathrm{n}=23)$. Conforme a análise do perfil dos discentes quanto à renda familiar, observou-se que a renda da maioria dos estudantes do curso gira em torno de três salários mínimos: $71,4 \%(n=31)$. No tocante à participação dos estudantes do curso nas ações extensionistas provenientes da UFC, 69\% (n=29) afirmam não participar das ações ofertadas pela presente instituição. Com relação ao enquadramento acadêmico como bolsista ou voluntário, 19,0\% (n=8) enquadram-se como bolsistas remunerados e 7,1\% (n=3) são voluntários em ações bolsistas.

É possível observar, portanto, que essa amostra é jovem, solteira e oriunda de escola pública, com renda familiar e maturidade de conteúdos, pois a maioria está no 7ํㅜ semestre, o que poderia possibilitar-lhes o interesse pelas ações promovidas pela extensão. Porém, o número dos envolvidos em atividades como bolsistas é pequeno $(n=11)$, o que pode indicar pouca permanência dos alunos na faculdade, por motivos de falta de oportunidade, responsabilidades no trabalho, desconhecimento ou desinteresse, como relatado por alguns discentes. Portanto, cabe refletir sobre a participação dos estudantes do curso e divulgação das ações extensionistas a fim de que possam integrarse ativamente nesse processo de consolidação de saberes com a possibilidade de que essas ações possam auxiliar em sua diversidade de aspectos e que envolvam também a formação no curso.

A Coordenadoria de Extensão do Benfica possui 207 programas e projetos, contabilizando 185 bolsas concedidas a universitários dos diversos cursos ofertados pela UFC. Contudo, a Faculdade de Educação, como unidade acadêmica em que se insere o curso de graduação de Pedagogia, possui apenas 16 projetos e cinco bolsistas de extensão, estudantes do curso de Pedagogia da UFC.

\subsubsection{Seção B: As ações extensionistas e sua organização na UFC}

Nesse momento, serão tratadas as análises realizadas sobre as 10 assertivas correspondentes à seção $\mathrm{B}$, elencadas de $\mathrm{A}$ a $\mathrm{J}$, as quais foram apresentadas aos 
estudantes do curso de Pedagogia da UFC sobre as ações extensionistas direcionadas a esse curso especificamente. Os itens sintetizados no instrumental foram pensados e construídos com base nas normas que disciplinam as atividades de extensão da UFC.

Esses itens tratam respectivamente: A - caráter dialógico das ações de extensão e desenvolvimento da universidade e sua relação com a sociedade; B - participação em atividades que viabilizam a flexibilização curricular, a integralização dos créditos e a clareza de suas atribuições; C - qualidade das ações de extensão como suporte à qualidade da formação do estudante; D - o conhecimento das ações de extensão promovidas; E - acompanhamento das ações de extensão sob o olhar das coordenações e/ou departamentos; F - relação das ações extensionistas e o impacto na ampliação; G acompanhamento das atividades desempenhadas pelo aluno através de plano de atividades sistemáticas; H - obstáculos para o acesso do estudante às ações de extensão; I - falta de tempo para participação das ações extensionistas; J - estrutura física e equipamentos adotados nas ações desenvolvidas.

Tabela 1 - Síntese dos princípios norteadores das ações de extensão da UFC

\begin{tabular}{cccccc}
\hline $\begin{array}{c}\text { Princípios } \\
\text { norteadores }\end{array}$ & $\begin{array}{c}\text { Não sei } \\
\text { responder }\end{array}$ & $\begin{array}{c}\text { Discordo } \\
\text { parcialmente }\end{array}$ & $\begin{array}{c}\text { Discordo } \\
\text { totalmente }\end{array}$ & $\begin{array}{c}\text { Concordo } \\
\text { parcialmente }\end{array}$ & $\begin{array}{c}\text { Concordo } \\
\text { plenamente }\end{array}$ \\
\hline A & $12,2 \%$ & $4,9 \%$ & $9,8 \%$ & $39,0 \%$ & $34,1 \%$ \\
B & $2,5 \%$ & $5,0 \%$ & $2,5 \%$ & $15,0 \%$ & $75,0 \%$ \\
C & $5,0 \%$ & $5,0 \%$ & $0,0 \%$ & $27,5 \%$ & $62,5 \%$ \\
D & $15,4 \%$ & $10,3 \%$ & $2,6 \%$ & $48,7 \%$ & $23,1 \%$ \\
E & $17,1 \%$ & $19,5 \%$ & $7,3 \%$ & $43,9 \%$ & $12,2 \%$ \\
F & $12,2 \%$ & $7,3 \%$ & $2,5 \%$ & $39,0 \%$ & $39,0 \%$ \\
G & $22,0 \%$ & $12,2 \%$ & $0,0 \%$ & $34,1 \%$ & $31,7 \%$ \\
H & $17,1 \%$ & $17,1 \%$ & $9,8 \%$ & $39,0 \%$ & $17,1 \%$ \\
I & $5,0 \%$ & $2,5 \%$ & $2,5 \%$ & $42,5 \%$ & $47,5 \%$ \\
J & $12,5 \%$ & $12,5 \%$ & $2,5 \%$ & $50,0 \%$ & $22,5 \%$ \\
\hline
\end{tabular}

Fonte: Elaboração própria (2016).

Sobre o item A, realizado a partir do questionamento destinado aos discentes do curso de Pedagogia, acerca do caráter dialógico das ações de extensão e desenvolvimento da universidade e sua relação com a sociedade, observou-se que 39\% $(n=16)$ concordam parcialmente com a premissa contida no instrumental, enquanto 
$34,1 \%(n=14)$ concordam plenamente com o fato de que a universidade dialogue com as ações extensionistas e formação do estudante de Pedagogia da UFC. Percebeu-se que todos concordam, de alguma forma, com as ações e o envolvimento na formação do pedagogo.

O item B questiona a participação do estudante de Pedagogia da UFC em atividades/iniciativas que viabilizem a flexibilização curricular, a integralização dos créditos e a clareza de suas atribuições, constatando-se que 75\% (n=32) concordam plenamente com o fato de que a formação do estudante, quando veiculada à participação em diversas ações extensionistas, sendo essas ações orientadas, acabam por constituirse como subsídios da ampliação das perspectivas de ampliação da formação do pedagogo.

$\mathrm{O}$ item $\mathrm{C}$ trata sobre a qualidade das ações de extensão como suporte à qualidade da formação do estudante de pedagogia da UFC, revelando que 62,5\% (n=26) concordam plenamente com o impacto positivo das ações extensionistas na formação discente. Assim, 90\% dos universitários pesquisados ratificam a qualidade dessas ações em sua formação.

O item D indaga sobre o conhecimento das ações de extensão que a UFC promove. Conforme análise realizada, verificou-se que 48,7 (n=20) dos respondentes afirmam conhecer totalmente as ações de extensão oferecidas pela instituição. Dessa forma, 23,1\% ( $n=10)$ expressam, de algum modo, conhecer essas ações, embora 15,4\% (n=6) afirmem desconhecer ou saber informar sobre essa questão, dado relevante para o setor de extensão.

A partir da análise da assertiva E contida no instrumental e da análise empreendida proveniente do acompanhamento das ações de extensão sob o olhar do discente das coordenações e/ou departamentos que estabeleçam o regimento e acompanhamento sistemático das atividades extensionistas realizadas pelos estudantes, constatou-se que 43,9\% (n=18) dos estudantes concordam parcialmente com tal assertiva, nesse caso, segundo os discentes, esse aspecto sugere aprimoramentos a fim de dinamizar esse apoio sistemático adotado pela instituição de ensino.

Observa-se, no item F, a relação das ações extensionistas e o impacto na ampliação. Diante disso, verificou-se, conforme a análise, que 39\% (n=16) concordam 
plenamente com tal afirmação, enquanto 31,7\% (n=15) concordam parcialmente; observou-se que 70,7\% de alunos percebem essa relação.

A análise do item $G$ versa sobre o acompanhamento das atividades desempenhadas pelo aluno através de plano de atividades sistemáticas, assim se observou que 31,7\% (n=13) concordam plenamente, enquanto 34,1\% (n=14) concordam parcialmente com esse desempenho.

Conforme o item $\mathrm{H}$, destinado aos obstáculos para o acesso do estudante de Pedagogia às ações de extensão e se os mesmos relacionam-se com a falta de planejamento do trabalho e com os objetivos determinados pela coordenação regulamentadora, observou-se que 39\% (n=16) concordam parcialmente com tal assertiva, enquanto $17,1 \%(n=7)$ concordam totalmente, assim pode-se ver a corresponsabilidade da coordenação sobre a organização desse planejamento para que se possibilite ao aluno ações direcionadas e em parceria com o setor de extensão.

No item I, relacionado à falta de tempo em razão de problemas familiares, além de outras atividades acadêmicas requeridas pela UFC que podem prejudicar a participação nas ações extensionistas desenvolvidas pela instituição, 47,5\% (n=20) concordam plenamente, enquanto 42,5\% $(\mathrm{n}=18)$ concordam parcialmente com tal assertiva. Com isso, pode-se inferir, então, a existência de mais um entrave vivido pelos alunos.

No item J, verifica-se a adequação da estrutura física e dos equipamentos adotados nas ações desenvolvidas consoante a percepção dos discentes do curso de Pedagogia. Segundo a análise, 22,5\% (n=21) concordam plenamente, ratificando as contribuições de espaços que facilitem o desenvolvimento do trabalho empreendido pelo estudante.

As ações de extensão constituem-se em possibilidades para a ampliação da formação inicial, proporcionando ao aluno vivências de conteúdos teóricos aprendidos em sala de aula. Assim, o envolvimento da coordenação do curso estudado, do setor de extensão e dos discentes-alvo constitui-se em um movimento necessário à qualidade dessas ações e sua amplitude no que se direciona à formação holística do pedagogo na UFC.

\section{Considerações finais}


Pode-se observar que a amostra de universitários é jovem, solteira e oriunda de escola pública, possuindo renda familiar e maturidade de conteúdos, o que pode possibilitar-lhes o interesse pelas ações promovidas pela extensão, porém alguns entraves foram percebidos durante a pesquisa, como as dificuldades pessoais dos alunos, a falta de organização da coordenação no direcionamento ou mesmo na proposta de atividades ligadas à extensão para os educandos e a não busca da extensão por esses setores/departamentos que se direcionam exclusivamente ao cuidado sobre o ensino.

Diante da estatística inferencial realizada, observou-se que a variável destacada denominada obstáculos de acesso não possui valor de dependência com o planejamento das ações extensionistas promovidas pela UFC. Entretanto, cabe destacar o papel da universidade na promoção e na organização sistemática do trabalho a ser desenvolvido pelo discente.

Considera-se que, apesar de entenderem a importância das ações de extensão para a formação e ampliação de saberes, os estudantes não participam das ações oferecidas pela instituição de ensino, assim cabe averiguar em pesquisas futuras esses motivos. Faz-se mister, portanto, estabelecer reflexões e ampliações do referido estudo para a possibilidade de geração de estratégias que direcionem os estudantes do curso de Pedagogia da UFC a estabelecerem ganhos significativos em sua formação a partir da participação das ações desenvolvidas.

\section{REFERÊNCIAS}

ANDRIOLA, W. B. Múltiplos olhares em torno da educação. Fortaleza: UFC, 2005.

BECKER, F. A origem do conhecimento e a aprendizagem escolar. Porto Alegre: Artmed, 2003.

BRUYNE, P.; HERMAN, J.; SCHOUTHEETE, M. Dinâmica da pesquisa em ciências sociais: os pólos da prática metodológica. Rio de Janeiro: Francisco Alves, 1977.

CORRÊA, E. J. (Org.). Extensão universitária: organização e sistematização/Fórum de Pró-Reitores de Extensão das Universidades Públicas Brasileiras. Coordenação Nacional do Forproex. Belo Horizonte: Coopmed, 2007.

DEMO, P. Avaliação qualitativa. Campinas: São Paulo, 2010.

LAKATOS, E. V. Fundamentos da metodologia científica. São Paulo: Atlas, 2003. 
LIMA, M. A. M. Auto-avaliação e desenvolvimento institucional na educação superior: projeto aplicado em cursos de Administração. Fortaleza: UFC, 2008.

MINAYO, M. C. O desafio do conhecimento: pesquisa qualitativa em saúde. Rio de Janeiro: Abrasco, 2007.

STAKE, R. E. Case studies. In: DENZIN, N. K.; LINCOLN, Y. S. (Ed.). Handbook of qualitative research. Thousand Oaks: Sage, 1994. p. 236-247.

STAKE, R. E. Conversando sobre avaliação. In: GOLDBERG, M. A. A.; SOUSA, C. P. (Org.). Avaliação de programas educacionais: vicissitudes, controvérsias, desafios. São Paulo: EPU, 1982. p. 57-62.

TYLER, R. W. General statement on evaluation. Journal of Educational Research, v. 35, n. 7, p. 492-501, 1942.

UNIVERSIDADE FEDERAL DO CEARÁ - UFC. Conselho de Ensino, Pesquisa e Extensão. Normas que disciplinam as atividades de Extensão da Universidade Federal do Ceará. Fortaleza: UFC, 1996.

UNIVERSIDADE FEDERAL DO CEARÁ - UFC. Diretrizes do curso de Pedagogia da UFC. Diretrizes regulamentadoras para o curso de Pedagogia. Fortaleza: UFC, 2013.

VIANNA, H. M. Avaliação educacional: teoria, planejamento e modelos. São Paulo: Ibrasa, 2000.

WEBER, M. Ensaios de sociologia. Rio de Janeiro: Zahar, 1963.

WEBER, M. Metodologia das ciências sociais. São Paulo: Cortez, 2001. 
The extension actions and their contributions for students of Pedagogy at Universidade Federal do Ceará (UFC)

\begin{abstract}
The present study deals with extension actions developed by Universidade Federal do Ceará for the formation of their students. The methodological approach bases itself on proposal of Bruyne et al. (1977). This is an exploratory and descriptive research, of quantitative and qualitative nature, with the university campus Benfica as the locus, and the students from the 3rd to the 7 th semester of Pedagogy course as the populational sample. In the quantitative aspect, we used the Statistical Package for the Social. By this way, it is possible to observe the importance of involvement in extension actions in the construction process of academic qualification and professional training of the students of that university.
\end{abstract}

Key-words: University extension; Academic qualification; Pedagogy.

\section{Las acciones de extensión y sus contribuciones para el discente de Pedagogía de la Universidad Federal del Ceará (UFC)}

Resumen: Este trabajo se propuso a estudiar las acciones de extensión desarrolladas por la Universidad Federal del Ceará para la formación de sus discentes. El abordaje metodológico se basó en la propuesta de Bruyne et al. (1977). Este estudio es de carácter exploratorio y descriptivo, con enfoque cuantitativo y cualitativo, el cual se realizó en el campus universitario del Benfica, utilizando como muestra poblacional a los discentes del 3. al 7.응 semestre del curso de Pedagogía. Sobre el aspecto cuantitativo, se llevó a cabo el análisis de los datos utilizando el Statistical Package for the Social Sciences. Mediante esa construcción, se observó la importancia de la participación en las extensiones en el proceso de construcción de la formación académico-profesional de los estudiantes de la referida universidad.

Palavras clave: Extensión universitaria; Formación académica; Pedagogía.

Original submetido em: 20 set. 2016

Aceito para publicação em: 25 maio 2017

Sobre os autores:

\section{Marcos Antonio Martins Lima}

Departamento de Fundamentos da Educação, Faculdade de Educação, Universidade Federal do Ceará.

\section{Ana Paula Vasconcelos de Oliveira Tahim}

Programa de Pós-graduação em Educação Brasileira, Universidade Federal do Ceará.

\section{Denize de Melo Silva}

Programa de Pós-graduação em Educação Brasileira, Universidade Federal do Ceará. 